OLIVEIRA, Marilene de L. Pafume. Missão Saraiva de 1864 ao Uruguai. Dissertação de Mestrado, Universidade de Brasília (UnB), 1985.

\title{
MISSÃO SARAIVA DE 1864 AO URUGUAI
}

\author{
Anderson Pafume \\ Biólogo \\ andpafume@hotmail.com
}

MISSÃO SARAIVA DE 1864 AO URUGUAI é o título da dissertação de mestrado defendida, em 1985, para a obtenção do Grau de Mestre em História das Relações Exteriores do Brasil, no curso de História, da Universidade de Brasília, Departamento de Geografia e História, sob a orientação do Professor Amado Luiz Cervo. Foi defendida pela historiadora Marilene de Lourdes Pafume de Oliveira, graduada pela Universidade Federal de Uberlândia e, tia e "segunda mãe" do resenhista. Foi ela fonte inspiradora para se fazer do conhecimento a melhor forma de se atingir o sucesso.

A dissertação, ora resenhada, trata da invasão do Império Brasileiro ao Uruguai, seus reais interesses e os diversos fatores que fizeram com que a "Missão Saraiva" se tornasse o maior conflito da América Latina. A missão recebeu esse nome por conta de seu conselheiro enviado, José Antônio Saraiva.

Os fatos se passaram por volta de 1864, época em que o Brasil Império e o Paraguai República disputaram a supremacia na região platina. A Europa, através da Inglaterra, também tinha interesses nessa região. Brasileiros latifundiários proprietários de terras no Uruguai, mais especificamente, às margens do rio da Prata, queixavam-se de atentados e violação de propriedades por parte das autoridades civis e militares desse país.

O que inspirou a autora a realizar o referido trabalho foi o interesse pelo envolvimento do Brasil no rio da Prata, por volta do séc. XIX. Tal envolvimento teve como pano de fundo a Missão Saraiva. Estados vizinhos e até mesmo a Inglaterra se envolveram nesse conflito, alguns com maior e outros com menor cumplicidade. Assim, o problema fundamental da pesquisa foram as preliminares do maior conflito latino-americano. Oliveira (1985) analisou a Missão Diplomática de 1864, através de documentos diversos, entre eles, os Anais do Senado e da Câmara dos Deputados, o Arquivo Histórico e a Correspondência Oficial (ofícios, notas e Recebido em 27/07/2017 / Aprovado para publicação em 01/10/2018.

OBSERVATORIUM: Revista Eletrônica de Geografia, v. 9, n. 3, p. 337-346. set./dez. 2018. 
Relatórios do Ministério dos Negócios Estrangeiros de 1863, 64 e 65).

Por se tratar de dados secundários, de documentos de difícil acesso, pobres em informação e, às vezes, até ilegíveis, os mesmos nem sempre são confiáveis. Tentou-se também contradizer o pensamento dominante na classe política da época, com raciocínios que os descaracterizassem.

Ainda, a autora pode questionar o caráter intervencionista do Império em suas relações com os países vizinhos, ao mesmo tempo em que tentou explicitar os motivos que ligaram a questão com o Uruguai, a Missão Saraiva e a guerra do Paraguai.

O primeiro item do trabalho intitula-se os "Motivos da Missão". A autora, baseando-se nos Relatórios dos Negócios Estrangeiros de 1864, apontou a situação insustentável criada pelo Estado Oriental do Uruguai, frente aos direitos dos brasileiros residentes nesse país, que sofreram com violências, perseguições e atentados, a maior parte foi realizada por autoridades civis e militares, os quais não foram submetidos a punições ou castigos. Mesmo com a política de neutralidade do Brasil para com os países do Prata, a gravidade da situação levou à "Missão Saraiva", última tentativa de boas relações entre Brasil e Uruguai. A Missão, por meio de seu conselheiro José Antônio Saraiva, desejou obter, além da punição aos responsáveis, a destituição dos agentes de polícia que têm realizado abuso; a indenização da propriedade, ou seja, a restituição dos prejuízos; liberdade aos brasileiros constrangidos ao serviço das armas e o respeito das autoridades Uruguaias para com eles; o reconhecimento dos direitos aos “concidadãos", instituídos pelas Notas Reversais de 28/11 e 03/12 de 1857; e, por fim, o respeito aos cônsules brasileiros residentes na República.

$\mathrm{Na}$ historiografia consultada, relatos de autores como Joaquim Nabuco, um dos grandes diplomatas do Império do Brasil, escritos em seu livro "Um Estadista do Império", afirmam que não se teve a intenção de incorporar o Uruguai ao protetorado Imperial, e que, ao Brasil, só interessava uma fronteira segura e sossegada, neutralismo que transparece durante a missão.

Andrés Lamas, Ministro Uruguaio escreve: "Não conheço um só estadista brasileiro que não repila com horror a ideia de incorporação do Estado Oriental ao Brasil”. D. Pedro II refere à Missão especial ao Uruguai como "o fim às queixas de ofensas aos direitos de nossos compatriotas, sem quebra da neutralidade".

Para Gonsalves (1977), a Missão foi uma política imperialista e intervencionista que vem de longa data, época em que o Brasil pertencia ao Reino Português, e que, após a derrota de Napoleão na Europa, aliados à Inglaterra, investem sobre a Província Oriental do Uruguai, 
conquistando-a e incorporando-a ao Império Português com o nome de Província Cisplatina. Em 1864, a situação política é outra. O Brasil já não faz parte do Reino Português. Para o referido autor, as intervenções armadas do Brasil são uma busca de prestígio e reconhecimento internacional, além de interesse territorial.

Galeano (1981) trata do intervencionismo Inglês à custa dos Países Platinos e tramado pelos interesses do Capitalismo Mundial. A Inglaterra, através de seu ministro Edward Thornton, participa das negociações entre Brasil e Uruguai, fato que selou a sorte do Paraguai.

Através de Flores, uruguaios se "dividiram". Conservadores se aliam ao Paraguai e liberais ao Império Brasileiro. Blancos versus colorados. Brasil resolve reforçar as fronteiras do Rio Grande do Sul e a frota de navios no rio da Prata. A recomendação é a de que as autoridades do Rio Grande do Sul não prestem auxílio à revolução de Flores, com promessa de punição a quem não se mantivesse neutro. Assim, o Brasil está a todo tempo escondendo suas reais intenções.

Geograficamente falando, o Brasil teve fortes motivos para a conquista de Montevidéu, visto que, controlando o rio Uruguai, o domínio sobre o rio da Prata e do rio Paraná seria efetivo.

O apoio da Inglaterra para a intervenção toma força através de Visconde de Mauá, que possui bancos no Uruguai, estes, que defendem interesses econômicos ingleses que, certamente, serão afetados com a perda da estabilidade política uruguaia. A compensação será o Paraguai.

Segundo a autora, "não há uniformidade nas fontes consultadas (...) uns são pela causa migracionista e expansionista, outros reforçam o neutralismo ou intervencionismo".

Posteriormente, o desenvolvimento deste trabalho evidenciou os reais motivos pelos quais o Brasil buscou o intervencionismo no Uruguai.

No item seguinte, “Desenvolvimento da Missão", Oliveira (1985) reforçou o estado de insegurança dos brasileiros residentes no Estado Oriental. Mesmo o Império manifestando-se contra tal situação, há um descaso total por parte do Uruguai. Diante tal situação, Saraiva foi enviado a negociar, instruído por João Pedro Dias Vieira, Ministro das Relações Exteriores do Império, em missão pacífica. Ao mesmo tempo, o Governo Imperial reforçou as fronteiras do Rio Grande do Sul, como medida de segurança. Essa medida fortaleceu Flores, o que denunciou um acordo entre o general e o governo brasileiro, apesar desse fato ser sempre negado. Ainda, o Brasil anunciou oficialmente que as forças militares ali postadas também "servirão para proteger e defender a vida, a honra e a propriedade de seus súditos". Tratavase, então, de uma forma de ameaça. Argentina solicitou explicações ao Brasil sobre o alcance 
desta missão. João Pedro Dias Vieira informou ser esse o ultimo apelo pacífico ao Uruguai.

Em 06 de maio de 1864, Saraiva chegou a Montevidéu, instruído oficialmente a se manter neutro. Dia $15 \mathrm{fez}$ a entrega da carta credencial ao governo do Uruguai. Inicialmente ambos concordaram em ceder, mantendo assim o caráter pacífico da missão. Não obstante, apesar da formalidade e diplomacia na qual foi tratado esse primeiro encontro, para o Uruguai, a missão especial brasileira apresentou-se como uma ameaça, principalmente, no que se refere às forças imperiais postadas na fronteira.

Uma correspondência entre José Berges, Ministro do Paraguai, e D. Felix Egusquiza, a menção ao apoio que Saraiva receberia da Inglaterra colocou em dúvida o caráter pacifico da missão. Também em correspondência oficial, Saraiva deixou transparecer a preocupação de que a missão não é tão pacífica, mesmo porque as negociações giraram em torno de uma situação de violência, vivida pelos súditos brasileiros no Uruguai. Expôs ainda, que essa situação colocara vários brasileiros a favor de Flores. Portanto, interessava ao Império desarmar esses brasileiros.

Em conferência com Herrera, Ministro de Estrangeiros da República, Saraiva concordou em reprimir a desordem que assolava o Uruguai, mas com as seguintes condições: de que fosse possível não usar da força e, a imposição de uma política de clemência que apagasse todos os ódios da guerra civil.

Argentina e Brasil se articularam, o que fez com que Uruguai não atendesse às solicitações impostas pela missão, isso porque se percebeu claramente que os envolvidos mantinham uma atitude dúbia.

A posição do Uruguai diante às reclamações brasileiras através da pessoa de Herrera foi de acusar o império de nada fazer para impedir que a situação em que se encontrava o país fosse tramada e organizada em território brasileiro, além de nenhuma providência no sentido de impedir sua propagação e desenvolvimento. Declarou o Império co-responsável em sua Guerra Civil, pois só as custas do auxílio brasileiro, via Flores, que a invasão se manteve.

Frente à Guerra intestina que se promovera no Uruguai, habitantes da fronteira não comprometidos com a revolução, em sua maioria proprietários brasileiros, dirigiram cartas às autoridades com pedidos de proteção.

Herrera coloca várias considerações em relação às reivindicações, entre elas de que ninguém se estabelece em um país estrangeiro, se não estiver de acordo com suas leis e autoridades. Desse modo, se a população brasileira do Estado Oriental é vítima das autoridades deste país, como não o são os demais estrangeiros que habitam este território; e 
ainda que os brasileiros se recusassem a vender suas propriedades ainda que por quantia considerável. Diante de acusações recíprocas, ficou claro que o Império propôs a intervenção política interna no Uruguai, usando como pretexto a situação dos brasileiros residentes neste país.

O Paraguai se colocou desde o início da Missão Saraiva a favor da integridade uruguaia e contra a intervenção. E o Brasil assumiu oficialmente a posição de negociar para se chegar a um fim sem quebrar a paz entre os países vizinhos. Saraiva apontou como prova de lealdade as ordens dadas ao Presidente da Província do Rio Grande do Sul pelo governo Imperial, proibindo toda intervenção de brasileiros nas lutas do estado vizinho. Para ele, $\mathrm{O}$ Brasil nada teve a ver com a questão partidária no Uruguai, onde muitos Blancos e Colorados disputavam o poder, o que foi evidenciado pela deposição de Flores em 1855. Ainda, a acusação uruguaia de que o exército de Flores é formado quase que exclusivamente por brasileiros e argentinos.

Ao ver falhar toda diplomacia em torno das negociações, Saraiva se decide pelo "ultimatum", claro, orientado pelo Império, que estabelece prazo para que Uruguai se posicione. Saraiva informa a Herrera que antes de emitir a última palavra do Império se entenderá com Mitre, Presidente Argentino, perante o qual se achava também credenciado. Então transpareceu que não havia justificativa para a interrupção de uma Missão especial brasileira, para a consulta de um terceiro país, a não ser que por trás já existissem outras intenções. Deste contato, Mitre se posicionou no sentido de que só a pacificação, seja ela por via direta ou indireta, com a união entre o governo Argentino e o Império, promovendo a formação de um governo provisório, seria a melhor solução, até que se pudessem realizar eleições no Uruguai.

Saraiva então redige o "ultimatum" e o entrega ao Ministério das Relações Exteriores do Uruguai, em 04/08/1864. Foram marcados 6 dias para resposta.

Enquanto isso, o Parlamento brasileiro posicionou-se contra a atitude arbitrária do Governo Imperial. Uruguai devolveu a nota "ultimatum" como injuriosa. Saraiva informou que o Brasil está disposto a suspender as represálias a qualquer momento, e que não teria empecilho a um novo entendimento.

Segundo Oliveira (1985), para as Repúblicas da América do Sul que só depois se organizaram internamente, o Brasil foi um perigoso inimigo. Além da ameaça que fez ao Uruguai, o sistema monárquico, através de uma constituição autoritária e de centralização do poder, fortaleceu o país, sendo que, nas Repúblicas, ao contrário, a característica foi a 
instabilidade.

No Uruguai, reinava o caos. Blancos e Colorados disputaram o poder de forma violenta. Esta guerra civil iniciara-se no governo de Bernardo Berro, em 1863, quando Flores, colorado, com o apoio de Mitre, invadiu o Uruguai. Os liberais brasileiros apoiaram essa revolução.

O motivo pelo qual este fato ocorreu é totalmente geográfico, visto que, na região do Prata, desenvolvia-se o comércio de gado, que fornecia além de outros produtos, o couro. Assim, esta região era estratégica, do ponto de vista do comércio mundial em vista destes produtos e da posição geográfica, o estuário platino, confluência dos rios Paraná, Paraguai e Uruguai. Por esse motivo, justificou-se a participação dos europeus representados pela Inglaterra neste conflito.

Em 1864, o presidente do Uruguai D. Atanásio Aguirre declarou-se firme em combater a rebelião de Flores. Contudo, suas condições, como governante, eram precárias. Somou-se a isso a situação deplorável do Uruguai em termos econômicos.

Elizalde, Ministro dos Estrangeiros argentino, propôs uma mediação. A última hora, o enviado Inglês Edward Thornton também se ofereceu como mediador. Assim, consolidou-se a entrada da Europa no conflito.

O governo Uruguaio, através de decreto, solicitou o desarmamento de seus cidadãos com vistas à paz, e sugeriu eleições no país. Pediu ainda ao exército que parasse a guerra civil. Flores exigiu mudança no ministério como condição para um acordo. Ministros uruguaios frente aos inconvenientes da guerra propuseram, por intermédio de carta entregue ao Presidente, que se observassem os seguintes pontos: igualdade de direitos aos cidadãos, independente de filiação partidária; o desarmamento de suas forças partidárias, e o reconhecimento dos postos adquiridos durante o conflito.

Segundo a autora, "percebe-se nesta negociação um jogo onde o alvo é o poder e onde ninguém quer perder". Diante este fato, Saraiva voltou a negociar diretamente com o governo uruguaio. Ele aconselhou Aguirre à formação de outro ministério, uma nova administração com homens íntegros e ativos, e que, com isso, se obteria o apoio, quem sabe, até mesmo Europeu. Mais uma vez não se chegou a acordo satisfatório.

Romperam-se as relações diplomáticas e os interesses brasileiros foram confiados às armas, na pessoa de Tamandaré, comandante das forças no rio da Prata. Em 20/10/1864, Tamandaré assinou com Flores o acordo secreto de Santa Luzia. O Uruguai pediu a intervenção do Paraguai, que declarou guerra ao Brasil. 
Nonque diz respeito ao caráter da Missão, a autora relatou os interesses comerciais e políticos ligados à região do Prata. Em 1864, Londres consolidava seu poder sobre o mundo, principalmente nas antigas colônias espanholas e no Brasil. O comércio de tecidos de algodão britânicos com os couros do rio da Prata e o café do Brasil garantiram a prosperidade da Inglaterra. Nesse período, os impostos de exportação e importação vinham sendo reduzidos, até se chegar a um comércio livre, que beneficiava, é claro, a Inglaterra. Assim, a política inglesa na região do Prata tinha como objetivo impedir que esta caísse em mãos norteamericanas e francesas.

O Paraguai era a única nação da América Latina que o capital estrangeiro não tinha “deformado". Seu desenvolvimento era autônomo, o que causava certo desconforto inglês. Daí o favorecimento pela Inglaterra na união da Argentina, Brasil e Uruguai para a destruição do Paraguai, favorecendo seus interesses comerciais na época.

Nesse contexto, Brasil ainda justificou a missão, considerando que Uruguai não tinha interesse em atender suas reivindicações, o que não traduz a realidade, visto que existiu farta documentação de reclamações também do Uruguai para com o Império. Ainda, visto que Saraiva vai para ao Uruguai munido de um "ultimatum", como considerar a missão como pacífica se desde seu início se faz acompanhar de uma ameaça? Esse "ultimatum" consta na historiografia, mas nunca foi analisado como o começo de uma intervenção. Na verdade, o Brasil apoiou uma revolução que dizimou o Uruguai. Paraguai, atento aos interesses do Brasil, ameaçou o Império com uma declaração de guerra. Brasil invadiu o Uruguai.

De acordo com Oliveira (1985), essa invasão serviu como estopim para a deflagração da Guerra do Paraguai, conflito que colocou em cheque todos os interesses dos países do cone sul, bem como interesses europeus.

Em consulta aos Anais do Senado, a autora relatou uma certa pressão do legislativo sobre o governo no sentido de se fazer ouvir, de se fazer respeitar. "Se as instituições como Exército e Marinha não servem para a defesa dos brasileiros, então mais vale que elas não existissem..." O Senado e a Câmara dos Deputados não foram, como deveriam ser, os legítimos representantes da sociedade brasileira nessa época. Nesses mesmos Anais, falou-se em manutenção da Independência e integridade do Estado Uruguaio, desenvolvimento de interesses recíprocos de amizade, comércio e vizinhança. Perceberam-se claramente as contradições.

Para a autora, o papel do Parlamento na missão é o de mero expectador, ou quando muito, o de inquiridor, visto a Constituição autoritária, despótica e centralizadora como a de 
1824. Houve uma concentração de poderes no executivo e pouca importância do legislativo. O Senado não foi chamado a opinar. O parlamento foi apenas informado dos acontecimentos. Não buscou esclarecer o povo.

Diante à suspeita de que os interesses do Império perante a intervenção no Uruguai são pretextos, e que os objetivos reais são o domínio de Montevidéu e do rio da Prata, interesses também da Inglaterra, pode-se observar a inutilidade dessa ação conjunta, uma vez que Brasil estava de relações cortadas com a Inglaterra. Na verdade, o pensamento oficial do Governo Imperial era de que esta luta nunca interessou ao Brasil. Outro ponto de controvérsia no Parlamento apontado pela autora se refere à pessoa de Flores, tido para alguns como revoltoso, para outros, como beligerante.

A posição do Império se dividiu. Para o Senador Pimenta Bueno, Flores é um beligerante disposto a iniciar uma guerra. C. Madureira, da Câmara dos Deputados se manifestou neutro diante às intenções de Flores, mas deixou claro que, pela mediação, o Governo brasileiro teria parte na instalação de um governo e, por isso, seria forçado a concordar com uma anistia. Para Ribeiro da Luz, deputado, os maiores prejudicados seriam os súditos do Império, já que as represálias se realizarão sobre as propriedades existentes nas fronteiras da Banda Oriental. Amaro da Silveira defendeu que Brasil deveria se posicionar no cenário internacional, pois só assim não seria menosprezado em seus direitos internacionais. O senador Dias Vieira, defendendo o nosso plenipotenciário, disse não ser possível exigir satisfações de um governo que, por sua fraqueza, não tivesse meios para fazer respeitar o que prometesse.

Na realidade, o governo brasileiro reconheceu a fragilidade do Oriental. Contudo, esta foi a missão mais aparatosa, e onde houve grandes gastos com o exército e a marinha. Percebeu-se, então, que a posição dos representantes do Parlamento brasileiro se dividiu em opiniões diversas, o que dificultou o entendimento e o andamento da missão, além de colocar em risco sua credibilidade no cenário mundial.

Importante destacar que, em seu estudo, a autora discutiu também as implicações da missão com a política Platina. No inicio, a missão apareceu como um ato diplomático. Contudo, percebeu-se certa incapacidade do Uruguai em solucionar pacificamente a questão, visto a sua situação de fragilidade pela evidência de uma guerra intestina. Mas muito mais do que a fragilidade do país, foi determinante dessa incompetência uruguaia e brasileira em negociar, os interesses internacionais que estavam em jogo. Por isso, a missão especial de 1864 com o "ultimatum", ser vista como pano de fundo para a generalização de um conflito 
na região Platina. Assim, Paraguai não viu com "bons olhos” esta questão. Na realidade, ele considerou a ocupação do território Oriental pelo governo Imperial como um atentado ao equilíbrio do Prata, ameaça à sua tranquilidade e dos demais países.

O texto de Oliveira esclarece que, quando surgiu a possibilidade de Flores dominar todo o país é que mudou a posição do Império, visto que, assim, o Brasil poderia contar no governo do Uruguai, com pessoa ligada a seus interesses, e nosso exército não teria necessidade de penetrar no Estado Oriental. Apesar dos esforços, teve-se a ocupação de Montevidéu, Paranhos foi enviado em missão especial para negociar as condições de paz. Foi estabelecido, assim, um governo provisório no Uruguai, conforme determinava a constituição. Este governo foi presidido por Flores, até que se reestabelecessem condições para eleições na forma da lei. Também foram devolvidas as propriedades confiscadas e realizado o desarmamento dos que serviram na guerra. Estas exigências representaram a consolidação de um governo no Uruguai que atendesse aos interesses brasileiros: a ditadura de Flores, com o respaldo das tropas do Império do Brasil e da Argentina. Assim, o Paraguai que sempre se posicionara contra a ocupação de terras uruguaias pelo Brasil, se estabeleceu como árbitro supremo entre as duas nações.

O Tratado de Aliança de 1850 entre o Paraguai e o Brasil estabeleceu o compromisso de busca de paz para a América Meridional. Ainda, se obrigaram através de auxílio recíproco a defenderem a livre navegação no rio Paraná até o rio da Prata, para ambas as nações. Portanto, a atitude que o Paraguai assumiu foi de encontro ao estabelecido no contrato supracitado.

Também a Inglaterra se interpôs na questão, mesmo estando de relações cortadas com o Brasil, oferecendo cooperação e lastimando a necessidade do Governo do Paraguai em cortar relações diplomáticas com o Império, sempre com vistas à condição de paz entre essas nações. A verdadeira intenção foi a expansão de sua área de influência.

Este Tratado de Aliança entre Brasil, Argentina e Uruguai foi uma farsa. Um ano antes de sua assinatura já estava pronto. Segundo Oliveira (1985), quando publicado em sua íntegra, provocou os mais inflamados protestos, tal é a natureza da rapinagem que estipula. E esta aliança é feita para abrir as portas do Prata para o mundo.

Em 14 de novembro de 1864, a República do Paraguai rompeu relações diplomáticas com o Brasil, em vista da ocupação Uruguaia. A guerra começou. Lopez foi para a guerra sem entender sua verdadeira causa. O fundamental foi que esta guerra foi feita para destruir a estrutura econômica do Paraguai, contrastante com o resto da América do Sul. O Imperialismo 
Inglês, destruindo o Paraguai, impediu a ascensão do único estado economicamente livre na América Meridional. Como citado pela autora, destruiu-se, com isso, o modelo de libertação que o Paraguai oferecia à América do Sul, em meados do séc. XIX.

A autora iniciou a conclusão com a seguinte frase: "vivemos uma crise política". Parece que se enquadra bem na atual circunstância em que se encontra hoje o Brasil. Como pensar em transformação, se a História que conhecemos é quase sempre uma versão duvidosa, construída para satisfazer interesses de classes e grupos dominantes.

Importa destacar também que o objetivo do trabalho de Oliveira (1985) foi realizar reflexões que pudessem clarear aspectos obscuros. Para isso, baseou-se no livro "As veias abertas da América Latina", onde o conflito é tratado como questão inerente ao sistema capitalista mundial, tramado pela Inglaterra.

Toda a documentação avaliada, a Missão Saraiva, especialmente, pelo "ultimatum", aparece como uma proposta de interferência nos assuntos internos do Uruguai, que reconheceu desde o início as pretensões do Império.

Quando a mediação fracassou, Saraiva estabeleceu no Uruguai um governo representativo de seus interesses, que garantiria o controle da situação dos brasileiros residentes neste país, mas provocava o rompimento diplomático com o Paraguai. Não é possível deixar de dizer que ao Paraguai interessava manter o equilíbrio na região, garantindo assim o seu progresso. Falou-se assim em imperialismo paraguaio, pelas suas pretensões expansionistas.

A autora finalizou com um parágrafo que expressa muitíssimo bem a atual situação a que se encontra hoje o Brasil e o mundo: "Vivemos hoje como ontem, uma crise. E, neste momento, o capitalismo mundial, após uma grave crise estrutural, buscou reencontrar o caminho da recuperação. Será este caminho a luta pelo extermínio da hegemonia das grandes potências?".

Neste passado, esta luta teria representado a eliminação da grande catástrofe sulamericana: a Guerra do Paraguai.

Por fim, considera-se que, trata-se de questão puramente geográfica, visto que a navegação nos rios do Prata e sua abertura ao comércio mundial colocaria em risco a autonomia econômica no Uruguai. Justifica-se assim, o interesse por estudantes do curso de Geografia, por esse tema, uma vez que é muito interessante para aqueles que pretendem estudá-lo e aprofundar no assunto, evidenciando, principalmente, os aspectos ditos geográficos. 